\title{
Luteolin inhibits multi-heavy metal mixture-induced HL7702 cell apoptosis through downregulation of ROS-activated mitochondrial pathway
}

\author{
YAFEI WANG ${ }^{1}$, HONG SU$^{1}$, XIN SONG $^{1}$, SAMUEL SELORM FIATI KENSTON $^{1}$, \\ JINSHUN ZHAO ${ }^{1}$ And YUANLIANG GU ${ }^{2}$
}

\begin{abstract}
${ }^{1}$ Department of Preventative Medicine, Zhejiang Provincial Key Laboratory of Pathological and Physiological Technology, School of Medicine, Ningbo University, Ningbo, Zhejiang 315211; ${ }^{2}$ Department of Prevention and Healthcare,

The People's Hospital of Beilun District, Beilun Branch Hospital of The First Affiliated Hospital of

Zhejiang University School of Medicine, Ningbo, Zhejiang 315800, P.R. China
\end{abstract}

Received April 12, 2017; Accepted October 17, 2017

DOI: 10.3892/ijmm.2017.3219

\begin{abstract}
With the rapid economic development in recent years, China is facing a great challenge due to heavy metal pollution. The heavy metals may enter the human body through ingestion of aqua products to cause great health risks. In the present study, the inhibitory effects of luteolin on the combined toxicity of multi-heavy metals (including zinc, manganese, lead, copper, cadmium, mercury, chromium and nickel) were investigated in HL7702 hepatocyte cells. An MTT assay demonstrated that $20 \mu \mathrm{M}$ luteolin significantly alleviated the multi-heavy metal mixture-induced cell death and morphological changes. Furthermore, $20 \mu \mathrm{M}$ luteolin significantly inhibited multi-heavy metal mixture-induced reactive oxygen species (ROS) generation, lipid peroxidation (malondialdehyde content) and caused a decrease in adenosine triphosphate levels in HL7702 cells. A JC-1 staining assay indicated that $20 \mu \mathrm{M}$ luteolin inhibited the mitochondrial membrane potentialreducing effect of the multi-heavy metal mixture. Apoptotic assays revealed that the multi-heavy metal mixture induced HL7702 cell apoptosis in a dose-dependent manner, which was significantly inhibited by $20 \mu \mathrm{M}$ luteolin. Western blot
\end{abstract}

Correspondence to: Dr Jinshun Zhao, Department of Preventative Medicine, Zhejiang Provincial Key Laboratory of Pathological and Physiological Technology, School of Medicine, Ningbo University, 818 Fenghua Road, Ningbo, Zhejiang 315211, P.R. China

E-mail: zhaojinshun@nbu.edu.cn

Mr. Yuanliang Gu, Department of Prevention and Healthcare, The People's Hospital of Beilun District, Beilun Branch Hospital of The First Affiliated Hospital of Zhejiang University School of Medicine, 1288 Lushan East Road, Beilun, Ningbo, Zhejiang 315800, P.R. China

E-mail: gurice@yeah.net

Key words: heavy metal, combined toxicity, apoptosis, reactive oxygen species, luteolin, inhibition, mitochondrial pathway analysis indicated that addition of luteolin to the multi-heavy metal mixture significantly alleviated cytochrome $c$ release from the mitochondria into the cytosol. In addition, $20 \mu \mathrm{M}$ luteolin had a significant inhibitory effect on multi-heavy metal mixture-induced cleavage of caspase-9, caspase- 3 and poly(adenosine diphosphate-ribose) polymerase-1 protein. Immunofluorescence staining demonstrated that addition of luteolin significantly alleviated caspase- 3 cleavage induced by the multi-heavy metal mixture. The present results suggested luteolin exerts its inhibitory effects of on multi-heavy metal mixture induced cell apoptosis through downregulation of the ROS-activated mitochondrial pathway.

\section{Introduction}

Rapid industrialization in China had certain drawbacks, and it is now facing a great challenge in heavy metal pollution. Processes of mining, smelting, industrial production, pesticide application as well as oil and other fuel combustion will inevitably result in widespread heavy metal pollution. China's main streams are suffering from varying degrees of heavy metal pollution (1-6). The various heavy metal elements in contaminated water may be accumulated in aquatic weeds, plankton and aquatic animals and finally enter the human body through various branches of the food chain (7).

Ningbo, an eastern coastal city in China, has $>7.8$ million inhabitants. In this area, the preferred daily diet mostly comprises aquatic products, including fish, shrimp, crab and shellfish. It is noteworthy that in recent years, the coastal waters and aqua products in the Ningbo area have been suffering from multi-heavy metal pollution, which mainly includes pollution with zinc, manganese, lead, copper, cadmium, mercury, chromium and nickel (8-10). Long-term consumption of aqua products may result in the accumulation of heavy metals and further human health hazards.

Multiple heavy metal elements may enter the human body simultaneously and the combined toxicity is complex due to their interaction. While the toxic molecular mechanisms of different heavy metals are not identical, they have certain 
effects in common. First, most heavy metal ions freely pass through the cell membrane and directly react with intracellular organelles and biological macromolecules, interfering with the intracellular calcium homeostasis and transport system (11). Furthermore, most heavy metals cause excessive generation of reactive oxygen species (ROS) and lead to organelle and DNA damage (12-15). These common points may be useful in searching for an effective antidote to antagonize the combined toxicity induced by multiple heavy metals.

Luteolin, a common flavonoid, occurs in broccoli, carrots, celery, cauliflower and peppers. Studies have confirmed that luteolin possesses important pharmacological properties, including antimicrobial, antiviral, anti-allergic, antioxidant, anti-inflammatory and anticancer effects (16-21). Other studies demonstrated that luteolin has an inhibitory effect on the toxicity induced by heavy metals. Zhou et al (22) suggested that luteolin protected SH-SY5Y cells against zinc-induced, ROS-mediated apoptosis. Liu et al (23) reported that luteolin regulated the redox imbalance, preserved mitochondrial function and depressed the caspase family-associated apoptosis induced by copper. Excessive ROS generation is associated with mitochondrial damage, while luteolin was reported to protect mitochondrial function through depression of ROS generation (24). In addition to zinc and copper, most other heavy metals also induce excessive ROS generation (25-30). Therefore, luteolin may be a potential effective antidote to prevent the combined toxicity induced by multiple heavy metals.

Therefore, the inhibitory effects of luteolin on the combined toxicity induced in HL7702 cells by a multi-heavy metal mixture, including eight common contamination metals identified in aqua products in the Ningbo area, were assessed and the underlying molecular mechanisms were investigated.

\section{Materials and methods}

Materials and reagents. $\left(\mathrm{CH}_{3} \mathrm{COO}\right)_{2} \mathrm{~Pb} \cdot 3 \mathrm{H}_{2} \mathrm{O}, \mathrm{CdCl}_{2} \cdot 2.5 \mathrm{H}_{2} \mathrm{O}$, $\mathrm{NiCl}_{2} \cdot 6 \mathrm{H}_{2} \mathrm{O}, \mathrm{MnCl}_{2} \cdot 4 \mathrm{H}_{2} \mathrm{O}, \mathrm{ZnSO}_{4} \cdot 7 \mathrm{H}_{2} \mathrm{O}, \mathrm{CuSO}_{4} \cdot 5 \mathrm{H}_{2} \mathrm{O}$ and $\mathrm{K}_{2} \mathrm{Cr}_{2} \mathrm{O}_{7}$ (analytical grades, 99.0-99.8\%) were all purchased from Sinopharm Chemical Reagent Co., Ltd. (Beijing, China). $\mathrm{CH}_{3} \mathrm{ClHg}$ (analytical grade, $\geq 99.0 \%$ ) was purchased from Dr Ehrenstorfer GmbH (Augsburg, Germany). MTT was supplied by Amresco ${ }^{\circledR}$ (Solon, OH, USA). Luteolin (analytical grades, $\geq 99.0 \%$ ) was obtained from Sigma-Aldrich (St. Louis, MO, USA). Bovine serum albumin (BSA) was from Sangon Biotech (Shanghai, China). The assay kits for the detection of lipid peroxidation (cat. no. S0131), ROS (cat. no. S0033), adenosine triphosphate (ATP; cat. no. S0026) and total protein were obtained from Beyotime Institute of Biotechnology (Shanghai, China). The mitochondrial membrane potential assay kit with JC-1 (cat. no. M8650) and the cell mitochondria isolation kit (cat. no. SM0020) were obtained from Solarbio Life Sciences (Beijing, China). The Alexa Fluor ${ }^{\circledR} 488$ Annexin V/Dead Cell Apoptosis kit (cat. no. V13241) was from Invitrogen (Thermo Fisher Scientific, Inc., Waltham, MA, USA). Antibodies B-cell lymphoma 2 (Bcl-2; cat. no. 2870), Bcl-2-associated X protein (Bax; cat. no. 2772), apoptotic protease activating factor 1 (Apaf1; cat. no. 8969), cleaved caspase-9 (cat. no. 7237), caspase-3 (cat. no. 9665), cleaved caspase-3 (Asp175; cat. no. 9661), cleaved PARP-1
Table I. Stock solution of the multi-heavy metal mixture prepared according to the proportions of daily consumption of each metal element through aqua products by an adult in the Ningbo area.

\begin{tabular}{lcc}
\hline $\begin{array}{l}\text { Heavy metal } \\
\text { element }\end{array}$ & $\begin{array}{c}\text { Concentration in } \\
\text { stock solution (mg/l) }\end{array}$ & $\begin{array}{c}\text { Consumption through } \\
\text { aqua products by a } \\
70 \text { kg adult (mg/day) }\end{array}$ \\
\hline $\mathrm{Pb}$ & 1.042 & 0.012 \\
$\mathrm{Cd}$ & 2.085 & 0.024 \\
$\mathrm{Hg}$ & 0.174 & 0.002 \\
$\mathrm{Cu}$ & 48.820 & 0.562 \\
$\mathrm{Zn}$ & 167.047 & 1.923 \\
$\mathrm{Mn}$ & 27.016 & 0.311 \\
$\mathrm{Cr}$ & 6.428 & 0.074 \\
$\mathrm{Ni}$ & 4.691 & 0.054 \\
Total & 257.303 & 2.962
\end{tabular}

(Asp214; cat. no. 9544), used for western blot analysis in the present study were obtained from Cell Signaling Technology, Inc. (Danvers, MA, USA). Poly(adenosine diphosphate-ribose) polymerase-1 (PARP-1; cat. no. sc-1562), GAPDH (cat. no. sc-25778), cytochrome $c$ (cat. no. sc-13561), pro-caspase-9 (cat. no. sc-7885) were all purchased from Santa Cruz Biotechnology, Inc. (Dallas, TX, USA). Goat anti-mouse IgG (cat. no. BA1050) and goat anti-rabbit IgG (cat. no. BA1054) were provided by the Boster Biological Technology (Wuhan, China). The HL7702 cell line was received from the Cell Bank of the Chinese Academy of Sciences (Shanghai, China).

Preparation of heavy metal mixture. The multi-heavy metal mixture, which included copper, mercury, cadmium, zinc, lead, manganese, nickel and chromium was prepared according to the proportions of daily intake of each metal through aqua product consumption by an adult in the Ningbo area (Table I) $(10,31)$. The sum of the concentrations of the eight heavy metal elements was used as the final concentration of the multi-heavy metal mixture.

Cell culture. HL7702 hepatocyte cells were maintained in RPMI-1640 medium (cat. no. SH30809.01; GE Healthcare Life Sciences, Little Chalfont, UK) containing $1 \%$ penicillin-streptomycin and 10\% fetal bovine serum from Tianhang Biological Technology (Huzhou, China) under standard culture conditions $\left(37^{\circ} \mathrm{C} ; 95 \%\right.$ humidified air and $\left.5 \% \mathrm{CO}_{2}\right)$.

MTT assay. HL7702 cells were seeded into a 96-well plate at a density of 10,000 cells/well in $200 \mu 1$ medium and cultured for $48 \mathrm{~h}$. The cells were then treated with multi-heavy metal mixture (concentrations of $0,16.73,19.30,21.87,24.44$ or $27.01 \mathrm{mg} / \mathrm{l})$ with or without luteolin $(20 \mu \mathrm{M})$. After $12 \mathrm{~h}$ of incubation, $10 \mu 1$ MTT solution $(3.5 \mathrm{mg} / \mathrm{ml})$ mixed with $90 \mu \mathrm{l}$ phenol red-free culture medium was added into each well, followed by further incubation in the dark for $4 \mathrm{~h}$. After the culture medium was discarded, $150 \mu 1$ dimethyl sulfoxide was added to each well. The plate was incubated on an incubator 

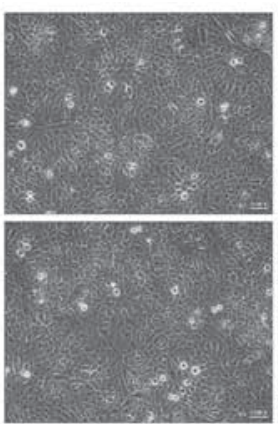

Control

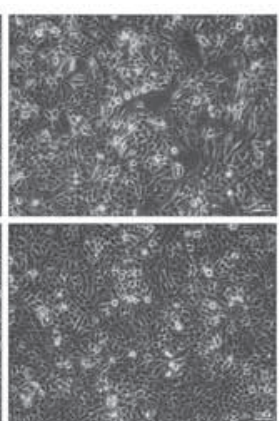

16.73

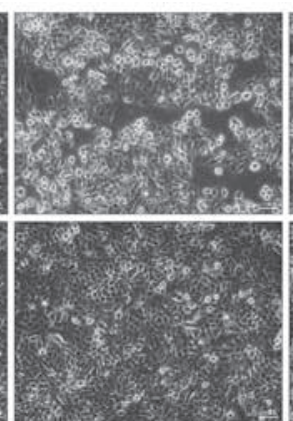

19.30

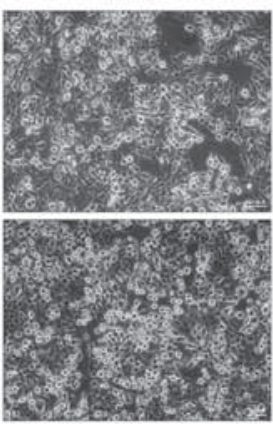

21.87

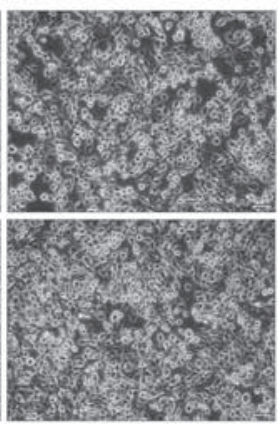

24.44

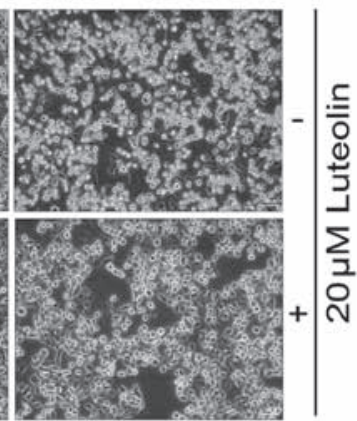

27.01

Mixture (mg/l)

Figure 1. Morphological changes of HL7702 hepatocyte cells after treatment with multi-heavy metal mixture alone or in combination with luteolin. Magnification, x40. Mixture, multi-heavy metal mixture.

shaker at room temperature for $15 \mathrm{~min}$. The optical density was measured at a wavelength of $492 \mathrm{~nm}$ using a microplate reader.

Lipid peroxidation detection. HL7702 cells were seeded into a 6-well plate at a density of 250,000 cells/well in $2.5 \mathrm{ml}$ medium and cultured for $48 \mathrm{~h}$. The cells were then treated with multi-heavy metal mixture $(0,16.73,19.30,21.87,24.44$ or $27.01 \mathrm{mg} / \mathrm{l})$ with or without luteolin $(20 \mu \mathrm{M})$. After $12 \mathrm{~h}$ of incubation, the cells were harvested and then lysed by adding $120 \mu \mathrm{l}$ Nonidet P-40 lysis buffer to each well. The lysate was centrifuged at $1,200 \mathrm{x}$ g for $15 \mathrm{~min}$ at $4^{\circ} \mathrm{C}$. The protein concentration was determined using the bicinchoninic acid method. Supernatant $(100 \mu \mathrm{l})$ was mixed with $200 \mu \mathrm{l}$ malondialdehyde (MDA) detection buffer and then boiled for $15 \mathrm{~min}$. After cooling to room temperature, the mixture was centrifuged at $1,000 \mathrm{x} g$ for $15 \mathrm{~min}$. The supernatant was then transferred into a 96-well plate $(200 \mu \mathrm{l} /$ well $)$ and the amount of lipid peroxidation was detected at a wavelength of $532 \mathrm{~nm}$ by a microplate reader. The MDA levels were normalized to the protein concentration.

ROS detection. Intracellular ROS levels were determined using a ROS detection kit. HL7702 cells were treated with multi-heavy metal mixture with or without luteolin as for the MTT assay in a black 96-well plate. The cells were then gently washed 2 times with serum-free medium. The cells were then incubated with $200 \mu \mathrm{l}$ serum-free medium containing $10 \mu \mathrm{M}$ $\mathrm{H}_{2} \mathrm{DCFDA}$ at $37^{\circ} \mathrm{C}$ for $35 \mathrm{~min}$. The fluorescence distribution of each well was detected by a fluorospectrophotometer (excitation wavelength, $488 \mathrm{~nm}$; emission wavelength, $535 \mathrm{~nm}$ ).

ATP detection. HL7702 cells were treated with multi-heavy metal mixture and luteolin as for the lipid peroxidation assay. Subsequently, they were gently washed 2 times with $4^{\circ} \mathrm{C}$ sterile PBS and lysed by adding $200 \mu 1$ Nonidet P-40 lysis buffer. The lysate was centrifuged at $12,000 \mathrm{x}$ g for $5 \mathrm{~min}$ at $4^{\circ} \mathrm{C}$. A $20-\mu 1$ aliquot of the supernatant was transferred into a dedicated centrifuge tube containing $100 \mu \mathrm{l}$ ATP detection buffer at room temperature. ATP standard solutions $(0,0.5,1,5,10,50$ and $100 \mu \mathrm{M})$ were used to obtain a standard curve. ATP levels were detected by measurement of the relative light unit value with a luminometer and were normalized to the protein concentration.
JC-1 staining assay. HL7702 cells were treated with multi-heavy metal mixture with or without luteolin as for the MTT assay in a black 96-well plate. Subsequently, $100 \mu \mathrm{l}$ phenol red-free culture medium mixed with $100 \mu \mathrm{l} \mathrm{JC-1}$ staining solution was added into each well and further incubated in the dark at $37^{\circ} \mathrm{C}$ for $20 \mathrm{~min}$. After gently washing the cells 2 times with $200 \mu \mathrm{l}$ JC-1 staining wash buffer $\left(4^{\circ} \mathrm{C}\right), 200 \mu \mathrm{l}$ phenol red-free culture medium was added into each well. The fluorescence of each well was observed under a fluorescence microscope and images were captured.

Apoptosis detection. Apoptosis was detected using the Alexa Fluor $^{\circledR} 488$ Annexin V/Dead Cell Apoptosis kit. HL7702 cells were treated with multi-heavy metal mixture and luteolin as for the lipid peroxidation assay. The cells were then harvested by EDTA-free trypsinization provided by Thermo Fisher Scientific, Inc. Following centrifugation at $67 \mathrm{x} g$ for $5 \mathrm{~min}$ at room temperature, the cells were resuspended in $500 \mu \mathrm{l}$ Annexin binding buffer containing $1 \mu \mathrm{l}$ propidium iodide dye and $5 \mu 1$ Alexa Fluor ${ }^{\circledR} 488$-conjugated Annexin V. The single-cell suspension was further incubated in the dark for $30 \mathrm{~min}$ and apoptosis was then monitored by flow cytometry.

Western blot analysis. HL7702 cells were seeded into 20x100 mm culture dishes at a density of 1,200,000 cells/dish in $10 \mathrm{ml}$ medium and cultured for $48 \mathrm{~h}$. The cells were then treated as described above and then gently washed 2 times with PBS at $4^{\circ} \mathrm{C}$

For whole-cell protein preparation, $500 \mu 1$ Nonidet P-40 lysis buffer containing $10 \mu \mathrm{M}$ phenylmethane sulfonyl fluoride was added into each dish to lyse cells on ice for $10 \mathrm{~min}$. The lysate was filled into Eppendorf tubes and centrifuged at $15,000 \times \mathrm{g}$ for $3 \mathrm{~min}$ at $4^{\circ} \mathrm{C}$. Of the supernatant, $350 \mu \mathrm{l}$ was used for whole-cell protein detection.

To prepare cytosolic protein, a cell mitochondria isolation kit was used according to manufacturer's instructions and $80 \mu l$ supernatant was used for the protein detection.

Protein concentrations were determined by the BCA method. Supernatant was mixed with $5 X$ loading buffer (4:1 in volume) and boiled for $5 \mathrm{~min}$.

Polyacrylamide stacking (6\%) gels and resolving (10\%) gels were used to separate proteins of different molecular weights. Then the proteins were transferred onto PVDF membranes, 


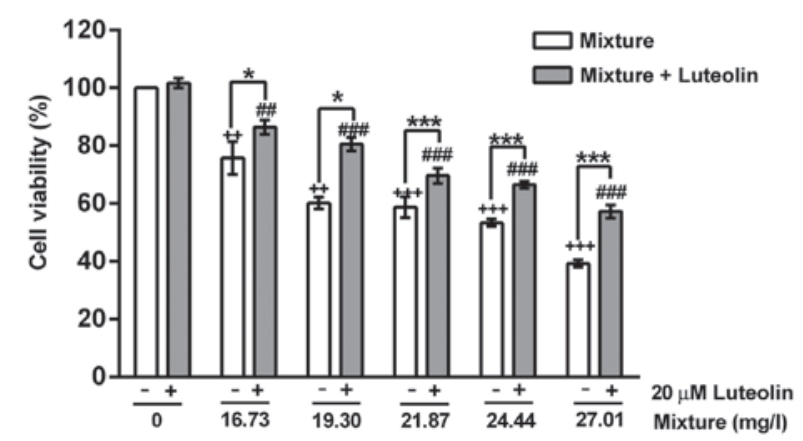

Figure 2. Viability of cells after treatment with multi-heavy metal mixture alone or in combination with luteolin. ${ }^{*} \mathrm{P}<0.05,{ }^{* * *} \mathrm{P}<0.001$, mixture alone compared with mixture + luteolin; ${ }^{++} \mathrm{P}<0.01,{ }^{++} \mathrm{P}<0.001$, compared with control - (without any treatment); ${ }^{\# \#} \mathrm{P}<0.01,{ }^{\# \# \#} \mathrm{P}<0.001$, compared with control $+20 \mu \mathrm{M}$ luteolin. Mixture, multi-heavy metal mixture.

blocked in 5\% skimmed milk for $3 \mathrm{~h}$ at room temperature and incubated for $12 \mathrm{~h}$ at $4^{\circ} \mathrm{C}$ with primary antibodies. After that, membranes were probed with secondary antibodies at room temperature for $1.5 \mathrm{~h}$. Immunoblotting was performed for Bcl-2, Bax, Apaf1, cytochrome $c$, pro-caspase-9, cleaved caspase-9, caspase-3, cleaved caspase-3 (Asp175), PARP-1, cleaved PARP-1 (Asp214) and GAPDH at 1:1,000 dilution. The Tanon imaging processing system (Tanon Science and Technology Co.,Ltd., Shanghai, China) was used for processing and evaluation of the western blots by ECL solution.

Immunofluorescence staining for cleaved caspase-3. HL7702 cells $(\mathrm{n}=50,000)$ were seeded onto a glass coverslip and maintained under standard culture conditions for $48 \mathrm{~h}$. The cells were treated with multi-heavy metal mixture and luteolin as described above. The glass coverslips were successively dipped in PBS (5 min, 2 times), 4\% paraformaldehyde (10 min), PBS containing Tween-20 (PBST; 5 min, 2 times), $0.1 \%$ Triton X-100 (10 min), PBST (5 min, 2 times), 1\% BSA-TBST blocking buffer $(2 \mathrm{~h}), 1 \%$ BSA-TBST solution containing cleaved caspase-3 rabbit antibody (2 h; 1:1,000 dilution at room temperature), PBST (10 min, 2 times), 1\% BSA-TBST solution containing goat-anti-rabbit antibody marked with Alexa Fluor ${ }^{\circledR} 488$ (2 h; 1:2,000 dilution at room temperature) and PBST (10 min, 2 times). The cell nuclei were stained with $10 \mu \mathrm{M}$ DAPI. The immunofluorescence staining of cleaved caspase-3 was captured by a fluorescence microscope.

Statistical analysis. Each experiment was performed three or more times. Differences within groups were analyzed using one-way analysis of variance and a post hoc least significant difference test with SPSS 13.0 (SPSS, Inc., Chicago, IL, USA). $\mathrm{P} \leq 0.05$ was considered to indicate a statistically significant difference.

\section{Results}

Cell viability and morphological changes. Treatment with multi-heavy metal mixture alone significantly reduced the cell viability and induced cell morphological changes in a dose-dependent manner, while addition of $20 \mu \mathrm{M}$ luteolin significantly inhibited these toxic effects induced by the multi-heavy metal mixture (Figs. 1 and 2).
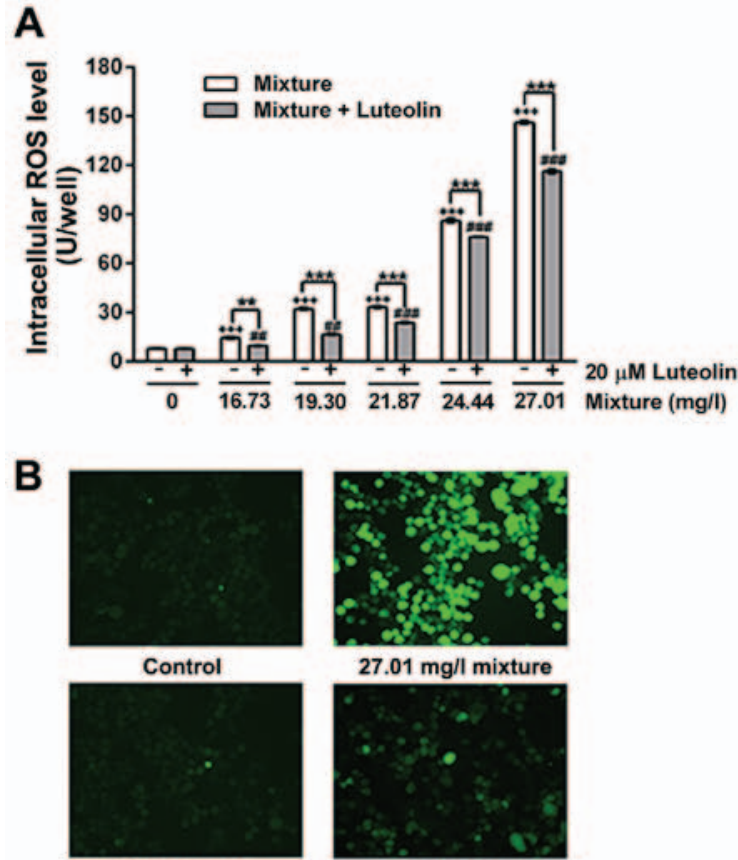

$20 \mu \mathrm{M}$ Luteolin

x40 magnification

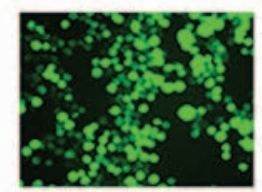

$27.01 \mathrm{mg} / \mathrm{l}$ mixture

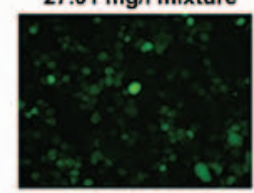

$27.01 \mathrm{mg} / \mathrm{l}$ mixture 列

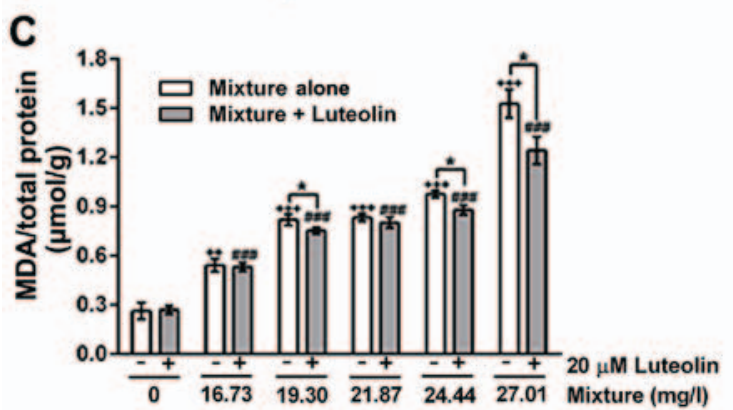

D

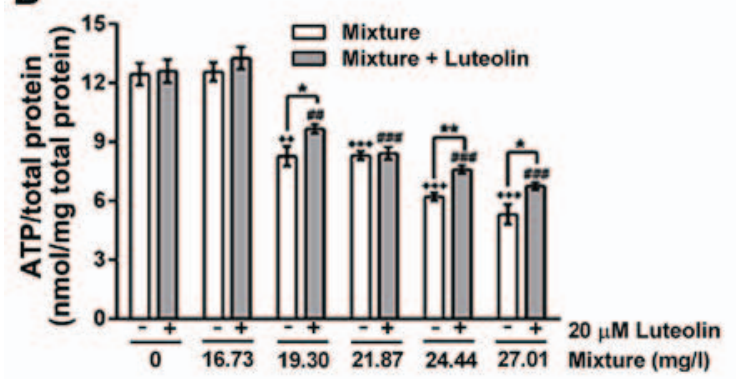

Figure 3. (A) ROS levels, (B) immunofluorescence images of ROS (magnification, x40), (C) MDA content and (D) ATP levels of cells treated with multi-heavy metal mixture alone or in combination with luteolin. ${ }^{*} \mathrm{P}<0.05$, ${ }^{* *} \mathrm{P}<0.01,{ }^{* * *} \mathrm{P}<0.001$, mixture alone compared with mixture + luteolin; ${ }^{++} \mathrm{P}<0.01,{ }^{+++} \mathrm{P}<0.001$, compared with control - (without any treatment); ${ }^{\# \#} \mathrm{P}<0.01,{ }^{\# \# \#} \mathrm{P}<0.001$, compared with control $+20 \mu \mathrm{M}$ luteolin. Mixture multi-heavy metal mixture; ROS, reactive oxygen species; MDA malondialdehyde; ATP, adenosine triphosphate.

ROS, lipid peroxidation and ATP level changes. The multi-heavy metal mixture induced intracellular ROS generation (Fig. 3A and B) and lipid peroxidation (Fig. 3C) in a dose-dependent manner, and decreased the intracellular ATP content (Fig. 3D). Addition of $20 \mu \mathrm{M}$ luteolin significantly inhibited the multi-heavy metal mixture-induced ROS generation and lipid peroxidation as well as the decrease of intracellular ATP. 

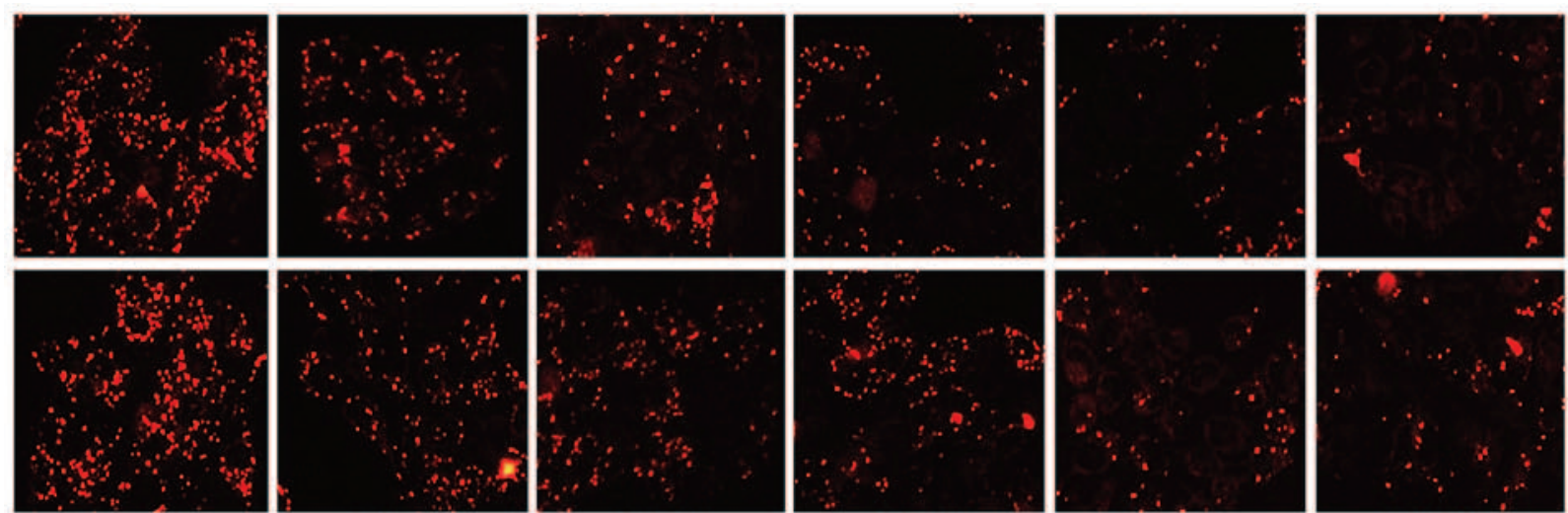

Control

16.73

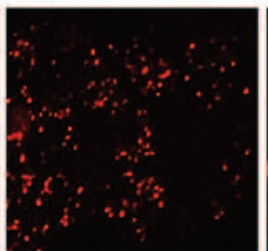

19.30

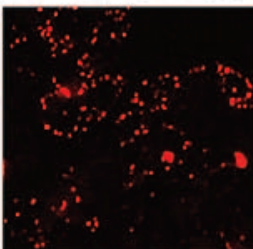

21.87

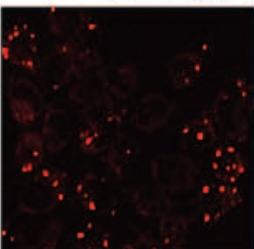

24.44

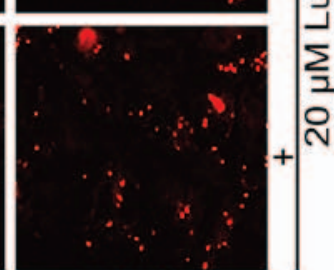

27.01

Mixture (mg/l)

Figure 4. Mitochondrial membrane potential changes after cells were treated with multi-heavy metal mixture alone or in combination with luteolin Mitochondria with high potential could be stained and vice versa. Magnification, x400. Mixture, multi-heavy metal mixture.
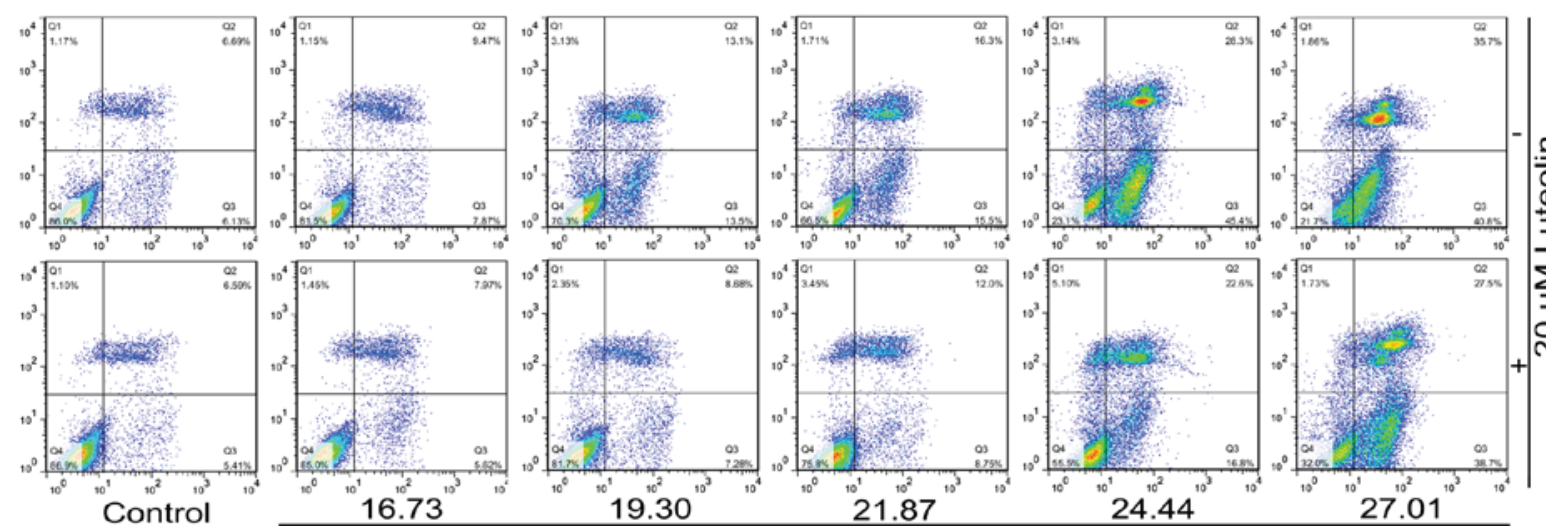

Mixture (mg/l)

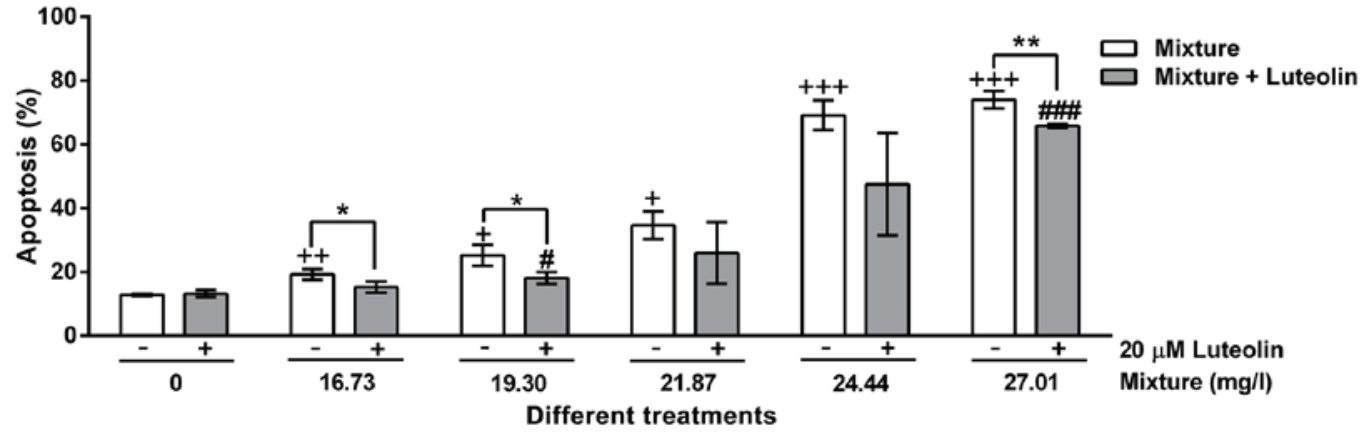

Figure 5. Apoptosis analysis after HL7702 cells were treated with multi-heavy metal mixture alone or in combination with luteolin. Cells were analyzed by flow cytometry after double-staining with Alexa Fluor ${ }^{\circledR} 488$ Annexin V (x-axis) and propidium iodide (y-axis). ${ }^{*} \mathrm{P}<0.05$, $^{* *} \mathrm{P}<0.01$, mixture alone compared with mixture + luteolin; ${ }^{+} \mathrm{P}<0.05,{ }^{+} \mathrm{P}<0.01,{ }^{+++} \mathrm{P}<0.001$, compared with control - (without any treatment); ${ }^{\#} \mathrm{P}<0.05,{ }^{\# \# \#} \mathrm{P}<0.001$, compared with control $+20 \mu \mathrm{M}$ luteolin. Mixture, multi-heavy metal mixture; Q, quadrant.

Mitochondrial membrane potential changes. With the increase in the multi-heavy metal mixture concentration, the mitochondrial membrane potential decreased gradually, while $20 \mu \mathrm{M}$ luteolin attenuated these changes (Fig. 4).

Apoptotic analysis. Multi-heavy metal mixture induced HL7702 cell apoptosis in a dose-dependent manner, while $20 \mu \mathrm{M}$ luteolin inhibited this effect (Fig. 5).

Effects on mitochondrial apoptosis-associated signaling proteins. Addition of $20 \mu \mathrm{M}$ luteolin inhibited the multi-heavy metal mixture-induced increase of the $\mathrm{Bax} / \mathrm{Bcl}-2$ ratio in the cells. Furthermore, $20 \mu \mathrm{M}$ luteolin significantly inhibited the multi-heavy metal mixture-induced increases of cleaved caspase-9, cleaved caspase-3 and cleaved PARP-1 protein. In addition, $20 \mu \mathrm{M}$ luteolin significantly alleviated the multiheavy metal mixture-induced cytochrome $c$ release from the mitochondria into the cytosol (Fig. 6).

Immunofluorescence staining results in cleaved caspase-3. Immunofluorescence staining revealed that at higher doses, multi-heavy metal mixture treatment alone induced significant 

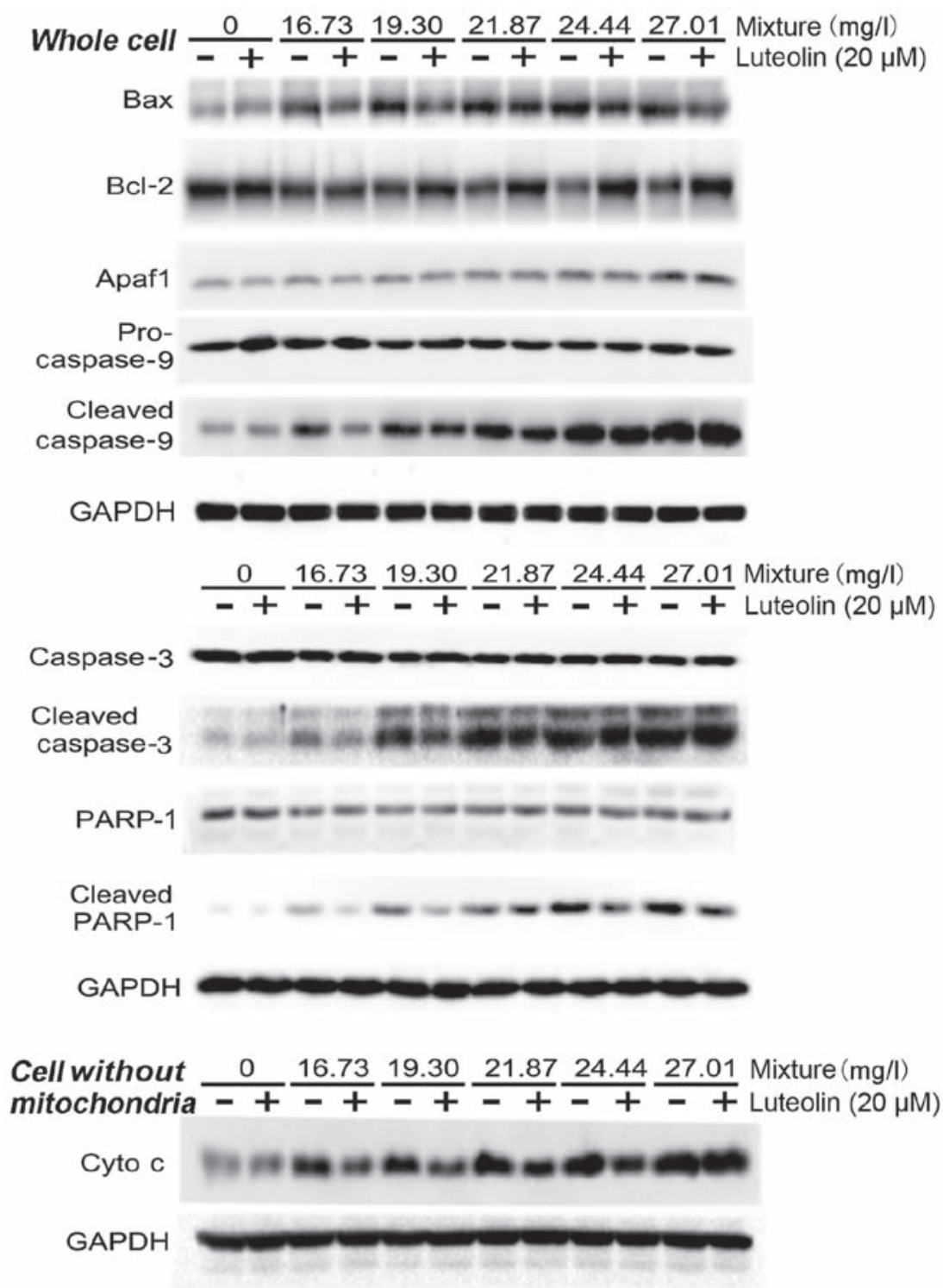

Figure 6. Mitochondrial apoptosis-associated signaling protein expression after HL7702 cells were treated with multi-heavy metal mixture alone or combined with luteolin. Mixture, multi-heavy metal mixture; Bcl-2, B-cell lymphoma 2; Bax, Bcl-2-associated X protein; Cyto $c$, cytochrome $c$; PARP-1, poly(adenosine diphosphate-ribose) polymerase-1; Apaf1, apoptotic protease activating factor 1.

caspase-3 cleavage (green color) in HL7702 cells, and addition of $20 \mu \mathrm{M}$ luteolin inhibited this effect (Fig. 7).

\section{Discussion}

The liver is an important multifunctional organ performing detoxification and metabolism of xenobiotics (32), substance synthesis and metabolic balancing of nutrients. In a previous study by our group, a MTT assay was used to screen various antioxidant chemicals for their protective effects and identified that $20 \mu \mathrm{M}$ luteolin significantly inhibited the cytotoxic effects if multi-heavy metal mixture in HL7702 cells. Therefore, HL7702 hepatocytes were used in the present study to investigate the combined toxicity of multi-heavy metal mixture and the inhibitory effects of luteolin as well as the underlying molecular mechanisms.

Normally, ROS generation and quenching are in a dynamic balance state due to the intracellular antioxidant system. Certain harmful extracellular factors may break this balance, resulting in excessive ROS generation beyond the cell scavenging ability to then induce organelle damage, abnormal expression of proteins or eventually cell death (33-35). Studies have demonstrated that most heavy metal ions cause excessive intracellular ROS generation $(12,22,36,37)$. The present results indicated that the multi-heavy metal mixture induced intracellular ROS generation in a dose-dependent manner, while the antioxidant luteolin had a significant quenching effect on this ROS generation. Lipid peroxidation is another indicator of cell damage from oxidative stress. Excessive ROS released from the mitochondria into the cytosol may induce cellular lipid peroxidation (38). The cellular MDA content is widely used as an index of lipid peroxidation levels. In the present study, luteolin was demonstrated to significantly prevent multi-heavy metal mixture-induced lipid peroxidation.

As an important energy molecule, ATP participates in most intracellular biogenic activities. The intracellular ATP levels decline once cells undergo apoptosis, necrosis or encounter adverse factors. The ATP detection results of the 

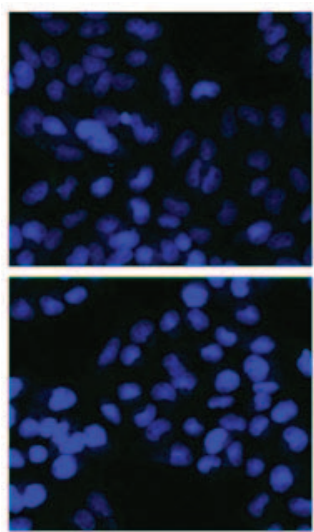

Control

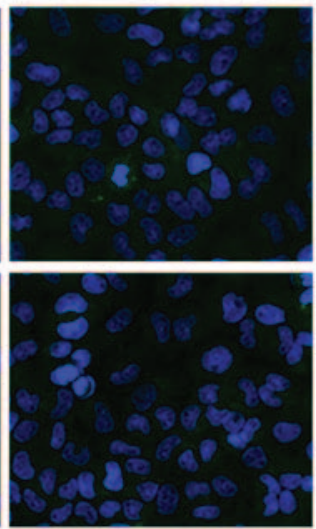

19.30
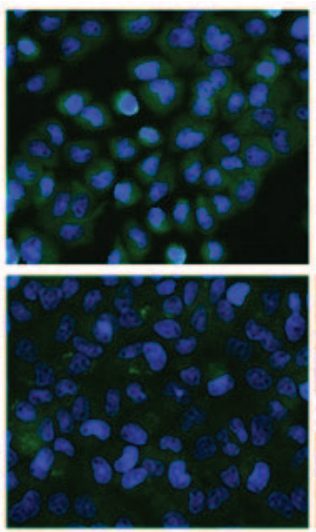

21.87

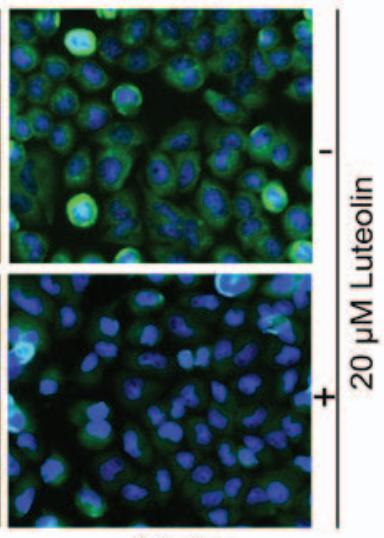

24.44

Mixture(mg/l)

Figure 7. Cleaved caspase-3 staining (green) of HL7702 cells treated with multi-heavy metal mixture alone or combined with luteolin. Cell nuclei were stained with DAPI (blue). Magnification, x400. Mixture, multi-heavy metal mixture.

present study suggested that $20 \mu \mathrm{M}$ luteolin significantly inhibited the multi-heavy metal mixture-induced effect on decreasing ATP levels. Excessive ROS and decreased ATP levels indicate impaired mitochondrial function (39-42). Mitochondrial JC-1 staining may be used to detect changes in the mitochondrial membrane potential. Under normal conditions, the JC-1 monomer aggregates in the mitochondrial matrix to form polymer J-aggregates (red color). Once the mitochondrial membrane potential decreases, JC-1 monomer cannot aggregate in the mitochondrial matrix, which results in less or no polymer J-aggregate formation (less or no red color). With increasing multi-heavy metal mixture concentration, the mitochondrial membrane potential gradually decreased, while $20 \mu \mathrm{M}$ luteolin significantly attenuated this change.

The simultaneous decrease of intracellular ATP levels and mitochondrial membrane potential often accompanies cell apoptosis. Apoptosis is an initiative action to implement programmed cell death (43), which is strictly controlled by multiple genes, including the protein families of $\mathrm{Bcl}-2$ and caspases, as well as the c-myc oncogene and P53 tumor suppressor gene (44-46). The death receptor pathways, including membrane receptor, cytochrome $c$ and caspase pathways, may be activated by a series of physiological and pathological signals $(47,48)$. In the present study, apoptosis was monitored by flow cytometry. The results indicated that the multi-heavy metal mixture induced HL7702 cell apoptosis in a dose-dependent manner, which was significantly inhibited by $20 \mu \mathrm{M}$ luteolin.

$\mathrm{Bcl}-2$ and Bax are proteins belonging to the Bcl-2 family and control the mitochondrial membrane permeability to regulate the release of cytochrome $c$ (45). Bax upregulates the permeability of the mitochondrial membrane accompanied with the release of cytochrome $c$ from the mitochondria into the cytosol, while Bcl-2 has the opposite role $(45,49)$. Cytochrome $c$ in the cytosol activates caspase family proteins and forms the cytochrome $c /$ Apaf1/caspase-9 apoptosome, which then leads to apoptosis (50). In the present study, mitochondrial apoptosis pathway-associated signal protein expression was detected by western blot analysis. The results suggest that treatment with the multi-heavy metal mixture led to a significant upregulation of the $\mathrm{Bax} / \mathrm{Bcl}-2$ ratio, as well as the levels of Apaf1, and cleavage of caspase-9, caspase- 3 and PARP-1. The immunofluorescence staining results in the intact HL7702 cells confirmed that the mitochondrial apoptosis pathway was activated (positive staining for cleaved caspase-3). Furthermore, these results also suggested that $20 \mu \mathrm{M}$ luteolin attenuated multi-heavy metal mixture-induced changes in signaling proteins of mitochondrial apoptosis pathways.

Therefore, the potential underlying molecular mechanisms of multi-heavy metal mixture-induced cytotoxicity may be summarized as follows: At first, the heavy metal ions enter the cells and induce intracellular ROS generation and mitochondrial damage. Subsequently, the permeability of the mitochondrial membrane is upregulated by the Bax protein, which leads to mitochondrial cytochrome $c$ release from the mitochondria into the cytosol and subsequent formation of the apoptosome. The apoptosome initiates the cascades of caspase-3 and PARP-1 cleavage, and eventually cell apoptosis. Luteolin inhibited multi-heavy metal mixture-induced apoptosis by quenching the excessive ROS and further by blocking the oxidative stress-mediated mitochondrial apoptosis pathway.

In conclusion, the present study demonstrated that the multi-heavy metal mixture containing eight common metals prepared according to the proportions in which daily intake of each metal occurs through aqua product consumption by an adult in the Ningbo area induced oxidative stress injury and mitochondrial damage in HL7702 cells. Luteolin protected HL7702 cells from multi-heavy metal mixture-induced toxicity through downregulation of the ROS-mediated mitochondrial apoptosis pathway. Luteolin may be beneficial to prevent the multi-heavy metal pollution-induced health hazards arising from long-term aqua product consumption. However, the inhibitory effect of luteolin on the combined toxicity of multi-heavy metals was only evaluated by in vitro experiments in the present study. A further in vivo study will be required to verify the above in vitro experimental results.

\section{Acknowledgements}

This study was partly supported by the National Nature Science Foundation of China (grant no. 81273111), Scientific 
Projects of Zhejiang Province (grant nos. 2015C33148 and 2015C37117), the Ningbo Scientific Innovation Team for Environmental Hazardous Factor Control and Prevention (grant no. 2016C51001), Zhejiang Key Laboratory of Pathophysiology (201703), and the KC Wong Magna Fund of Ningbo University.

\section{References}

1. Liu Z, Zhang Q, Han T, Ding Y, Sun J, Wang F and Zhu C: Heavy metal pollution in a soil-rice system in the Yangtze River Region of China. Int J Environ Res Public Health 13: 63, 2015.

2. Niu Y, Niu Y, Pang Y and Yu H: Assessment of heavy metal pollution in sediments of inflow rivers to Lake Taihu, China. Bull Environ Contam Toxicol 95: 618-623, 2015.

3. Pan Y and Li H: Investigating heavy metal pollution in mining brownfield and its policy implications: a case study of the Bayan Obo Rare Earth Mine, Inner Mongolia, China. Environ Manage 57: 879-893, 2016.

4. Yu R, Zhang W, Hu G, Lin C and Yang Q: Heavy metal pollution and $\mathrm{Pb}$ isotopic tracing in the intertidal surface sediments of Quanzhou Bay, southeast coast of China. Mar Pollut Bull 105: 416-421, 2016.

5. Zhang L, Liao Q, Shao S, Zhang N, Shen Q and Liu C: Heavy metal pollution, fractionation, and potential ecological risks in sediments from Lake Chaohu (Eastern China) and the surrounding rivers. Int J Environ Res Public Health 12: 14115-14131, 2015.

6. Zhong S, Geng H, Zhang F, Liu Z, Wang T and Song B: Risk assessment and prediction of heavy metal pollution in groundwater and river sediment: a case study of a typical agricultural irrigation area in Northeast China. Int J Anal Chem 2015: 921539, 2015.

7. Uluturhan E and Kucuksezgin F: Heavy metal contaminants in Red Pandora (Pagellus erythrinus) tissues from the Eastern Aegean Sea, Turkey. Water Res 41: 1185-1192, 2007.

8. Zhao J, Bowman L, Magaye R, Leonard SS, Castranova V and Ding M: Apoptosis induced by tungsten carbide-cobalt nanoparticles in JB6 cells involves ROS generation through both extrinsic and intrinsic apoptosis pathways. Int $\mathrm{J}$ Oncol 42: 1349-1359, 2013.

9. Zhijie Gao LW, Zheng H and Yao X: Analysis on concentration of heavy metals lead, mercury, cadmium, chromium in seafood in Ningbo in 2012. Zhongguo Shipin Weisheng Zazhi 26: 76-78, 2014

10. Lin X, Gu Y, Zhou Q, Mao G, Zou B and Zhao J: Combined toxicity of heavy metal mixtures in liver cells. J Appl Toxicol 36: $1163-1172,2016$

11. Verma R, Xu X, Jaiswal MK, Olsen C, Mears D, Caretti G and Galdzicki Z: In vitro profiling of epigenetic modifications underlying heavy metal toxicity of tungsten-alloy and its components. Toxicol Appl Pharmacol 253: 178-187, 2011.

12. Lou J, Jin L, Wu N, Tan Y, Song Y, Gao M, Liu K, Zhang X and He J: DNA damage and oxidative stress in human B lymphoblastoid cells after combined exposure to hexavalent chromium and nickel compounds. Food Chem Toxicol 55: 533-540, 2013.

13. Stephenson AP, Schneider JA, Nelson BC, Atha DH, Jain A, Soliman KF, Aschner M, Mazzio E and Renee Reams R: Manganese-induced oxidative DNA damage in neuronal SH-SY5Y cells: attenuation of thymine base lesions by glutathione and N-acetylcysteine. Toxicol Lett 218: 299-307, 2013.

14. Lankoff A, Banasik A, Duma A, Ochniak E, Lisowska H, Kuszewski T, Góźdź S and Wojcik A: A comet assay study reveals that aluminium induces DNA damage and inhibits the repair of radiation-induced lesions in human peripheral blood lymphocytes. Toxicol Lett 161: 27-36, 2006.

15. Bal W and Kasprzak KS: Induction of oxidative DNA damage by carcinogenic metals. Toxicol Lett 127: 55-62, 2002.

16. Kim JK, Kang KA, Ryu YS, Piao MJ, Han X, Oh MC, Boo SJ, Jeong SU, Jeong YJ, Chae S, et al: Induction of endoplasmic reticulum stress via reactive oxygen species mediated by luteolin in melanoma cells. Anticancer Res 36: 2281-2289, 2016.

17. Kanai K, Nagata S, Hatta T, Sugiura Y, Sato K, Yamashita Y, Kimura $\mathrm{Y}$ and Itoh $\mathrm{N}$ : Therapeutic anti-inflammatory effects of luteolin on endotoxin-induced uveitis in Lewis rats. J Vet Med Sc 78: 1381-1384, 2016

18. Fan W, Qian S, Qian P and Li X: Antiviral activity of luteolin against Japanese encephalitis virus. Virus Res 220: 112-116, 2016.
19. Majumdar D, Jung KH, Zhang H, Nannapaneni S, Wang X, Amin AR, Chen Z, Chen ZG and Shin DM: Luteolin nanoparticle in chemoprevention: in vitro and in vivo anticancer activity. Cancer Prev Res (Phila) 7: 65-73, 2014.

20. Kure A, Nakagawa K, Kondo M, Kato S, Kimura F, Watanabe A, Shoji N, Hatanaka S, Tsushida T and Miyazawa T: Metabolic fate of luteolin in rats: its relationship to anti-inflammatory effect. J Agric Food Chem 64: 4246-4254, 2016.

21. Francisco V, Figueirinha A, Costa G, Liberal J, Ferreira I, Lopes MC, García-Rodríguez C, Cruz MT and Batista MT: The flavone luteolin inhibits liver $\mathrm{X}$ receptor activation. J Nat Prod 79: 1423-1428, 2016

22. Zhou F, Qu L, Lv K, Chen H, Liu J, Liu X, Li Y and Sun X: Luteolin protects against reactive oxygen species-mediated cell death induced by zinc toxicity via the PI3K-Akt-NF- $\mathrm{kB}$-ERK-dependent pathway. J Neurosci Res 89: 1859-1868, 2011

23. Liu R, Meng F, Zhang L, Liu A, Qin H, Lan X, Li L and Du G: Luteolin isolated from the medicinal plant Elsholtzia rugulosa (Labiatae) prevents copper-mediated toxicity in $\beta$-amyloid precursor protein Swedish mutation overexpressing SH-SY5Y cells. Molecules 16: 2084-2096, 2011.

24. Choi EM: Luteolin protects osteoblastic MC3T3-E1 cells from antimycin A-induced cytotoxicity through the improved mitochondrial function and activation of PI3K/Akt/CREB. Toxicol In Vitro 25: 1671-1679, 2011.

25. Hossain S, Bhowmick S, Jahan S, Rozario L, Sarkar M, Islam S, Basunia MA, Rahman A, Choudhury BK and Shahjalal H: Maternal lead exposure decreases the levels of brain development and cognition-related proteins with concomitant upsurges of oxidative stress, inflammatory response and apoptosis in the offspring rats. Neurotoxicology 56: 150-158, 2016.

26. Karimi R, Vacchi-Suzzi C and Meliker JR: Mercury exposure and a shift toward oxidative stress in avid seafood consumers. Environ Res 146: 100-107, 2016.

27. Bagchi D, Bagchi M and Stohs SJ: Chromium (VI)-induced oxidative stress, apoptotic cell death and modulation of p53 tumor suppressor gene. Mol Cell Biochem 222: 149-158, 2001.

28. Iakimova ET, Woltering EJ, Kapchina-Toteva VM, Harren FJ and Cristescu SM: Cadmium toxicity in cultured tomato cells - role of ethylene, proteases and oxidative stress in cell death signaling. Cell Biol Int 32: 1521-1529, 2008.

29. Roth JA and Eichhorn M: Down-regulation of LRRK2 in control and DAT transfected HEK cells increases manganese-induced oxidative stress and cell toxicity. Neurotoxicology 37: 100-107, 2013.

30. Schmid M, Zimmermann S, Krug HF and Sures B: Influence of platinum, palladium and rhodium as compared with cadmium, nickel and chromium on cell viability and oxidative stress in human bronchial epithelial cells. Environ Int 33: 385-390, 2007.

31. Lin XL, Gu YL, Zhou Q, Mao GC, Ma DJ, Zhao JS and Zou BB Study: Joint toxicity of heavy metal mixtures related to proportions of fish consumption. J Ningbo Univ (NSEE) 29: 22-27, 2016 (In Chinese).

32. Guillouzo A, Corlu A, Aninat C, Glaise D, Morel F and Guguen-Guillouzo C: The human hepatoma HepaRG cells: a highly differentiated model for studies of liver metabolism and toxicity of xenobiotics. Chem Biol Interact 168: 66-73, 2007.

33. Gu Y, Wang Y, Zhou Q, Bowman L, Mao G, Zou B, Xu J, Liu Y, Liu K, Zhao J, et al: Inhibition of nickel nanoparticles-induced toxicity by epigallocatechin-3-gallate in JB6 cells may be through down-regulation of the MAPK signaling pathways. PLoS One 11: e0150954, 2016.

34. Asif M, Shafaei A, Jafari SF, Mohamed SK, Ezzat MO, Abdul Majid AS, Oon CE, Petersen SH, Kono K and Abdul Majid AM: Isoledene from Mesua ferrea oleo-gum resin induces apoptosis in HCT 116 cells through ROS-mediated modulation of multiple proteins in the apoptotic pathways: a mechanistic study. Toxicol Lett 257: 84-96, 2016.

35. Zhang L, Wang H, Xu J,Zhu J and Ding K: Inhibition of cathepsin S induces autophagy and apoptosis in human glioblastoma cell lines through ROS-mediated PI3K/AKT/mTOR/p70S6K and JNK signaling pathways. Toxicol Lett 228: 248-259, 2014.

36. Hosseini A, Sharifi AM, Abdollahi M, Najafi R, Baeeri M, Rayegan S, Cheshmehnour J, Hassani S, Bayrami Z and Safa M: Cerium and yttrium oxide nanoparticles against lead-induced oxidative stress and apoptosis in rat hippocampus. Biol Trace Elem Res 164: 80-89, 2015.

37. Verma K, Mehta SK and Shekhawat GS: Nitric oxide (NO) counteracts cadmium induced cytotoxic processes mediated by reactive oxygen species (ROS) in Brassica juncea: cross-talk between ROS, NO and antioxidant responses. Biometals 26: 255-269, 2013. 
38. Dutta RK, Nenavathu BP, Gangishetty MK and Reddy AV: Studies on antibacterial activity of $\mathrm{ZnO}$ nanoparticles by ROS induced lipid peroxidation. Colloids Surf B Biointerfaces 94: 143-150, 2012.

39. Mathy-Hartert M, Hogge L, Sanchez C, Deby-Dupont G, Crielaard JM and Henrotin Y: Interleukin-1beta and interleukin-6 disturb the antioxidant enzyme system in bovine chondrocytes: a possible explanation for oxidative stress generation. Osteoarthritis Cartilage 16: 756-763, 2008.

40. Akkerman JW, Rijksen G, Gorter G and Staal GE: Platelet functions and energy metabolism in a patient with hexokinase deficiency. Blood 63: 147-153, 1984.

41. Chinopoulos C, Tretter L and Adam-Vizi V: Depolarization of in situ mitochondria due to hydrogen peroxide-induced oxidative stress in nerve terminals: inhibition of alpha-ketoglutarate dehydrogenase. J Neurochem 73: 220-228, 1999.

42. Tretter L, Chinopoulos C and Adam-Vizi V: Enhanced depolarization-evoked calcium signal and reduced $[\mathrm{ATP}] /[\mathrm{ADP}]$ ratio are unrelated events induced by oxidative stress in synaptosomes. J Neurochem 69: 2529-2537, 1997.

43. Kerr JF, Wyllie AH and Currie AR: Apoptosis: a basic biological phenomenon with wide-ranging implications in tissue kinetics. Br J Cancer 26: 239-257, 1972.

44. Bennett M, Macdonald K, Chan SW, Luzio JP, Simari R and Weissberg P: Cell surface trafficking of Fas: a rapid mechanism of p53-mediated apoptosis. Science 282: 290-293, 1998.
45. Cory S and Adams JM: The Bcl2 family: regulators of the cellular life-or-death switch. Nat Rev Cancer 2: 647-656, 2002.

46. Enari M, Sakahira H, Yokoyama H, Okawa K, Iwamatsu A and Nagata S: A caspase-activated DNase that degrades DNA during apoptosis, and its inhibitor ICAD. Nature 391: 43-50, 1998.

47. Egger L, Madden DT, Rhême C, Rao RV and Bredesen DE: Endoplasmic reticulum stress-induced cell death mediated by the proteasome. Cell Death Differ 14: 1172-1180, 2007.

48. Eskes R, Desagher S, Antonsson B and Martinou JC: Bid induces the oligomerization and insertion of Bax into the outer mitochondrial membrane. Mol Cell Biol 20: 929-935, 2000.

49. Meichner K, Fogle JE, English L and Suter SE: Expression of apoptosis-regulating proteins $\mathrm{Bcl}-2$ and $\mathrm{Bax}$ in lymph node aspirates from dogs with lymphoma. J Vet Intern Med 30: 819-826, 2016.

50. Marsden VS, O'Connor L, O'Reilly LA, Silke J, Metcalf D, Ekert PG, Huang DC, Cecconi F, Kuida K, Tomaselli KJ, et al: Apoptosis initiated by Bcl-2-regulated caspase activation independently of the cytochrome $c /$ Apaf-1/caspase-9 apoptosome. Nature 419: 634-637, 2002.

(7) (9) This work is licensed under a Creative Commons

cc) AY At No Atibution-NonCommercial-NoDerivatives 4.0 International (CC BY-NC-ND 4.0) License. 